\title{
Le serment de Procné (Jean Geschwin, 1962): una alegoría dramática de los horrores de la guerra ${ }^{1}$
}

\author{
Antonio María MARTín RodRíGUEZ \\ Universidad de Las Palmas de Gran Canaria \\ antonio.martin@ulpgc.es
}

Recibido: 9 de diciembre de 2014

Aceptado: 4 de febrero de 2015

\section{RESUMEN}

Análisis de la tragedia legendaria en tres actos publicada en 1962 por el dramaturgo francés Jean Geschwin, en la que, a partir de una original recreación del mito de Progne y Filomela, se expresa la preocupación y el desasosiego provocados por las dos décadas de sangrientos conflictos bélicos casi ininterrumpidos que estaban desgarrando a Francia.

Palabras clave: Progne y Filomela. Teatro francés siglo XX. Jean Geschwin.

Martín Rodríguez, A.M., «Le serment de Procné (Jean Geschwin, 1962): una alegoría dramática de los horrores de la guerra», Cuad. Fil. Clás. Estud. Lat. 35.1 (2015) 159-183.

\section{Le serment de Procné (Jean Geschwin, 1962): \\ a dramatic allegory of war horrors}

\begin{abstract}
An analysis of the three-act tragedy published in 1962 by the French playwright Jean Geschwin; drawing from an original recreation of the Procne and Philomela myth, the play expresses the worries and unease caused by decades of ongoing, blood-drenched war conflicts which were then tearing France apart.
\end{abstract}

Keywords: Procne and Filomela. 20thc. French drama. Jean Geschwin.

Sumario: 1. La historia mítica de Progne y Filomela en el teatro francés. 2. La obra de Jean Geschwin. 3. Le serment de Procné. 3.1 El paratexto. 3.2 La versión canónica de la historia mítica y su adaptación en la obra de Geschwin. 3.3 Intención y sentido de la tragedia. 4. Conclusión. 5. Referencias bibliográficas.

\footnotetext{
${ }^{1}$ Este artículo se inscribe en el proyecto de investigación FFI2010-19829, financiado por el MINECO.
} 


\section{LA HISTORIA MÍTICA DE PROGNE Y FILOMELA EN EL TEATRO FRANCÉS}

Aun cuando las versiones dramáticas del mito de Progne, Filomela y Tereo, pujantes en el teatro europeo ya desde el siglo $\mathrm{XV}^{2}$, cobraron vida en Francia con notorio retraso con respecto a otras literaturas ${ }^{3}$, el teatro francés del siglo XVIII constituyó un fértil campo de cultivo para este truculento tema mitológico. Si bien los ensayos dramáticos anteriores a esa centuria son en Francia prácticamente inexistentes ${ }^{4}$, el llamado Siglo de las Luces vio representarse una serie de dramas que ponían en escena la vileza y el terrible castigo sufrido por el rey tracio Tereo, una insistencia temática que tal vez no fuera gratuita en un siglo que concluiría en el país vecino con la Revolución Francesa y la deposición y ejecución del soberano ${ }^{5}$. Ya el 20 de octubre de $1705^{6}$, en la Académie Royale de la Musique, se pone en escena por primera vez la

\footnotetext{
2 En 1429, en efecto, el veneciano Gregorio Correr (1409-1464) compuso una brillante Progne de cuño senecano, editada en 1558 en Venecia por Giovanni Ricci, aunque nos han llegado cuatro manuscritos del siglo XV, uno de ellos autógrafo y otros dos con correcciones del propio Correr. Un estado de la cuestión sobre el autor y su obra puede verse en Chevalier (2010, pp.101-207), que incluye una detallada introducción, una cuidada edición crítica de la tragedia y una traducción francesa, así como las pertinentes referencias a la bibliografía esencial. Una traducción inglesa, acompañada de una solvente edición, puede verse en Berrigan Tournoy (1980).

${ }^{3}$ En Italia, por ejemplo, Girolamo Parabosco publicó una Progne en 1548 ( $c f$. Bondi 2011) y en 1561 Lodovico Domenichi adaptó y tradujo al italiano la tragedia latina de Gregorio Correr, editada tres años antes; el texto de la versión de Domenichi, que se basó en la edición en Ricci, puede verse en Casarsa (1981), que ofrece también la edición de la Progne de Correr. La relación entre estas tres tragedias italianas ha sido analizada por Marcello (2008). También en esta misma época tenemos noticias de dos tragedias latinas escritas y representadas en Inglaterra, en el ámbito del teatro escolar, una Progne hoy perdida, obra de James Calfhill, que se puso en escena en Oxford el 6 de septiembre de 1566, en el marco de los festejos con que se celebró la visita de la reina Isabel a la ciudad universitaria, y una Philomela representada también en Oxford, en el colegio de St. John, el 29 de diciembre de 1607; cf. Martín Rodríguez (2010) y, para una edición hipertextual, Sutton (2006), que ofrece también una traducción inglesa; el texto original, en edición facsímil, puede verse en Richards (1982, pp.50-85). El testigo en el desarrollo dramático de este tema mítico durante el siglo XVII pasaría de Italia e Inglaterra a España, donde, aunque ya el XVI había conocido la Tragicomedia llamada Filomena (1564) de Juan de Timoneda y una versión anónima compuesta probablemente entre 1575 y 1580 , la Comedia Progne y Filomena que se conserva en el Ms. 14.640 de la Biblioteca Nacional (Ojeda Calvo 2006; Martín Rodríguez 2008b, pp.270-274), aparecerán en el XVII dos notables versiones, la Comedia de Progne y Filomena de Guillén de Castro (1618) y Progne y Filomena de Francisco Rojas Zorrilla (1636). Una visión de conjunto de las versiones dramáticas en la literatura española puede verse en Martín Rodríguez (2008a; 2008b, pp.255-322); cf., además, el análisis de Castañeda (2006). El siglo XVII conoce también una curiosa tragedia escrita en holandés, el Itys (1615) de Samuel Coster (1579-1665); un análisis de su dramaturgia a partir de sus piezas de tema clásico puede verse en Smits-Veldt (1986).

${ }^{4}$ Sabemos, con todo, que en 1694 se representó tres veces en el Palais Royal una ópera titulada Philomèle, escrita en colaboración por el duque Felipe II de Orléans (1674-1723) y su maestro de música, Marc-Antoine Charpentier (1643-1704). Al haber prohibido el duque que la obra se publicara, su texto no ha llegado hasta nosotros (Griffiths 1980, p.163).

${ }^{5}$ Resulta sorprendente, por ello, que no haya mención alguna de estos tratamientos dramáticos en el libro colectivo, por lo demás excelente, editado por Gély, Haquette y Tomiche (2006).

${ }^{6}$ Algunos de los datos que ofrecemos a continuación pueden consultarse en internet en el sitio CÉSAR (Calendrier électronique des spectacles sous l'ancien régime et sous la Révolution), en la dirección http:// www.cesar.org.uk/cesar2/.
} 
ópera Philomèle, con libreto de Pierre-Charles Roy (1683-1764) y música de Louis de Lacoste (ca. 1675-1750), repuesta el 8 de octubre de 1709, el 27 de abril de 1723 y el 19 de octubre de 1734, año en el que se imprime su texto ${ }^{7}$. Un claro indicio de su éxito y popularidad, además de la ya de por sí significativa serie de reposiciones, nos lo proporciona la hilarante parodia de Alexis Piron (1689-1773), titulada igualmente Philomèle $(1723)^{8}$, compuesta, con toda probabilidad, al albur y para aprovecharse del éxito de la segunda de las mencionadas reposiciones. Doce años más tarde, en 1735, un año después, significativamente, de la tercera de dichas reposiciones, aparece el Térée de Paul Desforges-Maillard (1699-1772) ${ }^{9}$, al que siguieron otras dos tragedias homónimas, una de ellas, de fecha incierta y hoy perdida, obra de François-Louis Cocquard (1700-1782), y la otra, publicada en 1753, de Jean-Baptiste Guys ${ }^{10}$. Ocho años después, en 1761, M. de la Volierre, pseudónimo de Pijon (1736-1766), puso en escena y publicó una Progné, igualmente en clave trágica, año en el que también Antoine-Marin Lemierre (1733-1793), el 25 de marzo, hizo subir a las tablas un nuevo Terée $^{11}$. Doce años después, en fin, el 3 de junio de 1773, en la Salle des Machines de París, Antoine Renou (1731-1806) ${ }^{12}$ estrenó su tragedia Térée et Philomele, publicada ese mismo año en Amsterdam y París. El tema de Tereo, por tanto, anduvo subiendo y bajando de los escenarios en Francia prácticamente hasta las vísperas mismas de la Revolución ${ }^{13}$, y podemos decir que su desarrollo dramático en la literatura europea durante este siglo fue acaparado prácticamente por los dramaturgos franceses ${ }^{14}$.

\footnotetext{
${ }^{7}$ Un análisis de esta tragedia lírica puede verse en Martín Rodríguez (2009). Para la vida y la obra de Roy, el autor del texto, sigue siendo esencial la monografía de Polinger (1930). Sobre Louis de Lacoste, el autor de la música, $c f$. Hunter (1980).

${ }^{8}$ Sobre su figura y su obra pueden verse los estudios generales de Verèb (1997) y Connon (2007). Un análisis de la obra ofrece Martín Rodríguez (2011).

${ }^{9}$ Aun cuando en el Calendrier anteriormenente citado (http://www.cesar.org.uk/cesar2/titles/titles. php?fct=edit\&script_UOID=137019) se indica, haciéndose eco de la información suministrada por Brenner (1947, $\mathrm{n}^{\circ} 5479$, p.56), que la tragedia se publicó en 1735, en el volumen titulado Poésies de Mlle Malcrais de la Vigne, Paris, Vve Pissot, el cotejo de dicha obra evidencia que se trata de un error, de modo que el texto de la tragedia está, seguramente, perdido. Mlle Malcrais de la Vigne es un pseudónimo inventado por el poeta bretón para burlarse de sus críticos.

${ }^{10}$ Según señala Fortia d’Urban (1817), era natural de Marsella y miembro de la Academia de Caen. A propósito de su Térée, se indica que se halla en él «de la facilité et quelque fois de la chaleur», y que la pieza no llegó a representarse.

${ }^{11}$ Repuesto el 28 de febrero de 1787, con notables modificaciones, y publicado ese mismo año. Un análisis de la tragedia ofrece Martín Rodríguez (2008c). Nociones generales sobre el teatro de Lemierre pueden verse en Marchal-Ninosque (2003).

${ }^{12}$ La fuente básica para la vida y la obra de Renou es la necrológica redactada por su amigo Nicolas Ponce, publicada originalmente en el Moniteur Universel de julio de 1809, y luego reproducida total o parcialmente en otros formatos; $c f$., por ejemplo, Ponce (1824). Una amplia reseña sobre su vida y su obra ofrece Fialcofschi (2009, pp.242-299), que toma como punto de partida la necrológica de Ponce y la biografía, un tanto sesgada y más bien poco simpatética, pero llena de datos interesantes, de Jouin (1905). Un análisis de la tragedia puede verse en Martín Rodríguez (2013).

${ }^{13}$ Como se indicó más arriba, el Terée de Lemierre se repuso en febrero de 1787, publicándose su texto ese mismo año, dos años antes, por tanto, de la Revolución.

${ }^{14}$ Fuera de Francia, las tragedias dedicadas a nuestro tema en el XVIII son escasas. Debemos citar, en primer lugar, la Progne de Veronica Cantelli de Tagliazucchi (1700-1770), publicada en Módena en 1766;
} 
Pero, curiosa y sorprendentemente, el tratamiento dramático de este sugestivo tema mítico sufrirá después del siglo XVIII un eclipse comparable al que había sufrido desde la Antigüedad hasta bien entrado el Renacimiento. No hay, en efecto, al menos que sepamos, drama alguno sobre esta materia durante el siglo XIX y la primera mitad del pasado siglo, pero en torno a 1960 dos dramaturgos de segunda fila y prácticamente desconocidos, el uno italiano, Alfonso Fontanella, y el otro francés, Jean Geschwin, tratarán, de modo independiente y con no mucho éxito ${ }^{15}$, de resucitar en el molde dramático este añejo tema. Presentamos en este trabajo un primer acercamiento a la versión de Geschwin.

\section{LA OBRA DE JEAN GESCHWIN}

La producción literaria de Jean Geschwin, escritor prácticamente desconocido y ausente, de hecho, de los manuales y libros de referencia sobre la literatura francesa del siglo $\mathrm{XX}^{16}$, se concentra sobre todo en el drama, y en particular en el ámbito de la tragedia. A juzgar por lo que puede deducirse del lugar de publicación de sus obras, casi todas ellas editadas en la Imprimerie de la Charité de Montpellier, su lugar de nacimiento, o, al menos, de residencia, debe situarse en esa zona del Midi francés, muy probablemente en Sète ${ }^{17}$, donde edita también algunas de sus obras. Parece probable que la mayoría de ellas haya sido publicada en régimen de auto-edición ${ }^{18}$.

Entrando ya, con un poco más detalle, en el recuento de su obra, su producción dramática - de cuya representación no tenemos constancia- se encuentra reunida en cuatro volúmenes, editados en la Imprimerie de La Charité de Montpellier, tres de ellos recopilatorios de sus tragedias y dramas históricos y uno de sus comedias. Sus tragedias y dramas históricos se contienen en Théâtre en prose (1962), Tragédies (1977) y Tragédies nouvelles (1990). En el primero de ellos se incluyen una tragedia legendaria (Le serment de Procné) y un drama histórico ambientado en la época turbulenta de las guerras de religión (La fille de Poltrot ${ }^{19}$ ). El segundo reúne seis piezas, Cléopâtre, Eponine, Charles VI, La fille de Poltrot, Louis XIII y L'homme au masque

una semblanza de la autora puede verse en Rovani (1856, pp.445-447). En segundo lugar, debe mencionarse la desmayada tragedia Progne y Filomena de Tomás Sebastián y Latre (1772), una especie de reescritura políticamente correcta del drama de Rojas Zorrilla; sobre esta refundición pueden verse los análisis de McVay (1994), Vellón Lahoz (1994) o Martín Rodríguez (2008b, pp.310-321).

${ }^{15}$ Ninguna de las dos obras, por ejemplo, figura en el prestigioso repertorio de Reid (1993).

${ }^{16}$ De hecho, el catálogo de la Biblioteca Nacional de Francia registra puntualmente sus publicaciones, pero no ofrece dato alguno sobre el autor, circunstancia cuando menos extraña para un escritor de la segunda mitad del siglo XX. Lo mismo ocurre en Internet, donde sus obras aparecen en páginas relacionadas con libreros o distribuidores, pero nada se encuentra sobre su persona.

${ }^{17}$ La comuna de Sète pertenece al distrito de Montpellier, incluido a su vez en el departamento de Hérault, en la zona conocida genéricamente como Languedoc o Rosellón.

${ }^{18}$ Así, en la ficha de la BNF correspondiente a su libro Tous les poèmes (1969), en el apartado correspondiente a «Publication», leemos: « [34-Sète] ([36, rue Henri-Barbusse]): 1'auteur, 1969».

19 Jean de Poltrot (1537-1563), señor de Méré, se alineó durante las guerras de religión en el bando protestante. Tras asesinar al cabecilla del bando católico, el Duque de Guisa, fue a su vez torturado y ejecutado. 
de $f e r^{20}$. El tercero, en fin, contiene tres obras: Le démon de Midi, La Bérécina y Napoléon IV. Como puede verse, sus temas preferidos son la historia de Francia, en todas sus etapas ${ }^{21}$, y el mundo clásico, al que corresponden tres de sus piezas, dos de tema propiamente histórico, Cléopâtre ${ }^{22}$ y Eponine ${ }^{23}$, y una de tema mitológico, Le serment de Procné, sobre la que nos centramos en este artículo.

En lo que se refiere a las comedias, se encuentran recopiladas en un volumen titulado Comédies Sétoises (Geschwin 1983), que contiene cinco piezas: Une femme encombrante, Duel à Sète ${ }^{24}$, Le crime de la rue Barbusse ${ }^{25}$, Le trésor de Rommel y Ali, Baba et les quarante voleurs. Secuenciadas, al igual que las tragedias, por un orden cronológico - no de composición, sino en función de la época en la que cada obra se ambienta- no del todo estricto, todas ellas se sitúan en Sète, respectivamente en los primeros años treinta, hacia 1960, en 1955, hacia 1970 y en 1981.

Geschwin es autor, en fin, de cuatro libros de poesía (Geschwin 1966; 1968; 1978; 1969).

Sin necesidad de entrar en un análisis de fondo de su teatro, resulta evidente que, de las dos grandes tendencias opuestas e inconciliables que conforman la drama-

${ }^{20}$ Cléopâtre, Charles VI y Louis XIII habían sido publicadas anteriormente en volumen conjunto en 1959, recopilación de sus dramas escritos en verso; La fille de Poltrot, en 1962, junto con Le serment de Procné, y L'homme au masque de fer en 1963, junto con la comedia Un duel à Sète.

${ }^{21}$ La folie de Charles VI, que es como se titula Charles VI en el cuerpo de su recopilación de tragedias de 1977, se desarrolla en el Hôtel Barbette, en el Marais, el 23 de noviembre de 1407; La Fille de Poltrot, en Reims, el 29 de noviembre de 1594; Louis XIII, en el Louvre, el 17 de abril de 1617; L'homme au masque de fer comienza en el Louvre y el Palais Mazzarin en junio y agosto de 1659 y termina en el Louvre en 1679; Bérécina es el nombre de una batalla en la que el ejército napoleónico, ya en franca retirada, sufrió en 1812 una derrota estrepitosa en tierras de lo que hoy es Bielorrusia, y Napoleón IV, en fin, es el título pomposo y vacuo que los partidarios del depuesto Napoleón III dieron a su hijo Napoleón Eugenio Luis Bonaparte (1856-1879) a la muerte de su padre en 1873, y del que apenas si pudo disfrutar, pues murió en Sudáfrica pasados apenas cinco años, en la guerra provocada por el levantamiento zulú. Eponine, por su parte, se retrotrae a la protoFrancia que constituye la Galia ocupada por Roma en el siglo I de nuestra era y en Le serment de Procné, como tendremos ocasión de ver, hay claros ecos de la Francia desgarrada por la guerra de Argelia en la segunda mitad del pasado siglo.

${ }^{22} \mathrm{He}$ aquí lo que comenta el propio autor como colofón tras el texto de la tragedia: «Cette tragédie est une juste réhabilitation de Cléopâtre, dont l'histoire et la légende font un monstre sacré, sans cœur et sans scrupules. C'était une femme simple, sensible et émouvante comme beaucoup d'autres, qui se débattit dans une situation d'une rare intensité dramatique» (Geschwin 1977, p.[50]).

${ }^{23}$ Eponine es la esposa de Julio Sabino, uno de los caudillos de la revuelta de la Galia contra Roma en 69-70. Tras la derrota, Sabino, a quien creen muerto, vive durante varios años oculto en una gruta, mientras su esposa lo llora vestida de luto durante el día y se une con él durante la noche. Descubierto al fin y conducido ante Vespasiano, su esposa suplica en vano por su vida, y pide al menos poder unirse a él en la muerte. Con un poco de exageración, porque el tema ha gozado de cierta popularidad a lo largo de la historia, Geschwin señala lo siguiente: «Pour la première fois, j’ai porté à la scène la célèbre héroine gauloise et son malheureux époux. Mais mon ambition a été surtout d'intéresser quelques lecteurs à cette période assez obscure, mais combien dramatique, de notre histoire. Par ailleurs, je suis assez satisfait d'avoir mis en parallèle la décadence de l'empire romain et celle d'un siècle ignorant et grossier qui nous mène on ne sait où» (Geschwin 1977, p.98). En esta tragedia, por tanto, se dan la mano las dos temáticas principales de los dramas de Geschwin, la historia de Francia y la historia clásica.

${ }^{24}$ Publicada anteriormente, junto con L'homme au masque de fer, en Geschwin (1963).

25 Publicada anteriormente en solitario en Geschwin (1964). 
turgia francesa de posguerra -el teatro tradicional y el teatro del absurdo-, nuestro dramaturgo se inscribe sin ambages en la primera. Más aún, dentro de este teatro de corte tradicional la posición en la que podría situárselo es la del más conspicuo arcaísmo, habida cuenta de que, como ha señalado Dejean (1987, p.9), no es solo que en el teatro francés de ese periodo no se escriban ya tragedias en verso ${ }^{26}$, sino que, en realidad, prácticamente no se escriben tragedias, al menos en el sentido exacto del término ${ }^{27}$. Geschwin, además, parece, al menos en sus tragedias, inmune a algunos de los rasgos comunes de los dramaturgos de la época, como son las concesiones al lenguaje cotidiano y el influjo del cine.

Es verdad, con todo, que en sus dramas están presentes algunos de los rasgos comunes que comparten dramaturgos y público en los primeros años de posguerra. En primer lugar, lo que bien podríamos llamar el trauma de la guerra, que, aunque había acabado en los campos de batalla en 1945, continuaba dentro de cada hombre que había experimentado sus horrores o sus consecuencias en casi cualquier parte del globo $^{28}$. En segundo lugar, la convicción del valor didáctico, en un plano simbólico, del teatro, concebido como un formidable instrumento de formación moral. Pero lo cierto es que hacia 1955 el público francés se había cansado ya del teatro de mensaje, de los escritores militantes y, en suma, del drama didáctico, para volverse a un Nouveau Théâtre enteramente alejado de las propuestas humanistas y centrado en la enfatización de lo absurdo del mundo (Dejean 1987, p.26), que acabará haciendo sitio al teatro de provocación que se impondrá en los sesenta. Y es en ese contexto, precisamente, cuando fragua Geschwin, tan fuera de onda, la mayoría de sus obras.

\section{LE SERMENT DE PROCNÉ}

\subsection{EL PARATEXTO}

Le serment de Procné es definida por el propio Geschwin como «tragedia legendaria en tres actos». Al principio del libro se incluye un interesante Avant-Propos en

\footnotetext{
${ }^{26}$ Algunas de las tragedias de Geschwin, en efecto, están, anacrónicamente, escritas en verso, como Cléopâtre, La folie de Charles VI o Louis XIII. En ninguna de las comedias, afortunadamente, sucumbió nuestro dramaturgo a esta tentación.

${ }^{27}$ La única excepción destacable, según Dejean, sería Montherlant. En realidad, no se trata tanto de que el sentido de la tragedia desaparezca como de que sufre una radical transformación, en la que, como recuerda Brunel (2002, p.197), el héroe trágico en lucha con un destino que lo abruma deja sitio a una especie de antihéroe irrisorio, incluso grotesco, en inútil combate con un mundo reificado y un lenguaje cuya aptitud para la comunicación se ve severamente contestada. En el teatro del absurdo, la condición trágica del hombre se manifiesta más bien en el descubrimiento, en medio del estupor y de la incomprensión, de un universo cuyas reglas no se entienden. Esta experiencia, en fin, del hombre de nuestro tiempo de sentirse inútil e insignificante en un mundo absurdo, incomprensible e incongruente, es la que hace de nuestra vida un nuevo tipo de tragedia, como señalan Bancquart-Cahné (1992, p.387).

28 «La seconde guerre mondiale ne finit pas avec Hiroshima. Certes, depuis le jour où fut lancée la première bombe atomique, le conflit armé se trouva virtuellement terminé. Mais, éteinte sur les champs de bataille de 1'Europe et du Pacifique, la guerre continue à retentir en chaque homme dans le monde» (Dejean 1987, p.11).
} 
el que se aducen las razones que llevaron al autor a la conjunción de las dos obras en un mismo volumen -la guerra endémica que desgarra a Francia- y se ofrecen disculpas al lector por las alusiones a la coyuntura presente que podrán encontrarse en el texto $^{29}$. La guerra a la que se hace referencia parece, obviamente, en un primer nivel, la de la independencia de Argelia (1954-1962), que vivía, precisamente, sus últimos coletazos $^{30}$, aunque el empleo del adjetivo endémico apunta más bien a la sensación que experimentaban muchos franceses de un fatídico encadenamiento de conflictos bélicos, que podría arrancar, en efecto, con la derrota y ocupación alemana durante la Segunda Guerra Mundial (1939-1945), y encadenarse después con la Guerra de Indochina (1945-1954), que concluyó con la derrota de Francia y la independencia de la Indochina francesa (Camboya, Laos, Vietnam), y la guerra de Argelia (1954-1962), además de los procesos de descolonización en el África francesa que empezaban ya a fraguarse.

Todavía en el ámbito del paratexto, la página, sin numerar, dedicada a las $d r a-$ matis personae, que más abajo detallaremos, incluye, en el margen superior, una reminiscencia de Esquilo ${ }^{31}$.

La acción de desarrolla en Lénos, en Tracia, en la Antigüedad, y el decorado es único a lo largo de los tres actos: un salón del palacio de Tereo que da a unos jardines.

\subsection{LA VERSIÓN CANÓNICA DE LA HISTORIA MÍTICA Y SU ADAPTACIÓN EN LA OBRA DE GESCHWIN}

La versión canónica de esta historia mítica para las literaturas modernas, como es bien sabido, es la que modeló Ovidio en las Metamorfosis ${ }^{32}$, que podríamos resumir como sigue: el rey de Atenas, Pandión, recibe la ayuda salvadora del tracio Tereo, con el que casa a su hija Progne. La boda se celebra en medio de funestos augurios, que no impiden la inmediata concepción de un heredero. La pareja vive feliz en Tracia durante unos años, hasta que Progne concibe la funesta idea de pedir a su esposo que se dirija a Atenas en busca de su hermana. En Atenas, Tereo se enamora fulminantemente de su cuñada, aunque oculta sus sentimientos y consigue el permiso de Pandión para que la muchacha emprenda el viaje, en el curso del cual la viola, le corta

29 «Ce n'est pas sans raison - on le verra aisément- que j’ai réuni ces deux ouvrages en un seul volume. La guerre endémique dont la France est déchirée m'en a donné l'idée et le dessein. On relèvera sans doute quelques allusions à la conjoncture présente, mais j'espère que les lecteurs trouveront la chose assez naturelle. Je les en remercie d'avance».

${ }^{30}$ La guerra concluyó con el reconocimiento por parte de Francia de la independencia de Argelia en el tratado de Evian, firmado el 5 de julio de 1962. La tragedia se compuso en 1961, y el libro se acabó de imprimir, como se señala en el colofón, en el primer trimestre de 1962, cuando la guerra, por tanto no había aún terminado.

31 «Pur ou non, tout ce sang versé finira bien par réveiller les dieux».

32 Cf. Ov.Met.6.424-476. Para la formación de la historia desde sus orígenes hasta la versión canónica ovidiana siguen siendo esenciales los estudios ya clásicos de Cazzaniga (1950-1951) y Mihailov (1955), que deben completarse con los más recientes de Martín Rodríguez (2002) y Monella (2005). 
la lengua, la encierra en una granja fuertemente custodiada y da cuenta a Progne de su supuesta muerte. Progne le erige un cenotafio y la llora durante un año, al cabo del cual Filomela consigue comunicarse con ella por medio de una tela en la que borda su historia, que le hace llegar por medio de una sirvienta. Cuando Progne se entera de la verdad, aprovecha las fiestas de Baco para liberar a Filomela al frente de un cortejo de ménades. Una vez en palacio, las hermanas traman y ejecutan una feroz venganza: dan muerte al niño Itis, guisan sus miembros y sirven su carne a su padre. Al final del banquete, cuando el soberano tracio pregunta, ominosamente, por su hijo, Filomela le arroja a la cara la cabeza del crío. Las hermanas huyen y se transforman en ruiseñor y golondrina, mientras Tereo se convierte en abubilla, un ave cuya apariencia, con su vistosa cresta y su largo pico, hace pensar en un guerrero.

Geschwin mantiene a los cuatro personajes esenciales de la historia, Progne, Filomela, Tereo e Itis ${ }^{33}$-aunque Filomela no aparece nunca en escena-, pero amplía el número de hijos de Progne y Tereo, que son ahora tres, haciendo de Itis no el unigénito, sino el más pequeño y por ende el más querido para su padre ${ }^{34}$, mientras que el heredero del reino es el primero de los hijos varones, Adis, a quien se presenta como un adolescente apenas, aunque preocupado ya por los problemas del reino ${ }^{35} \mathrm{y}$ consciente de la formación que debe adquirir en todo momento para llegar a ser un buen rey ${ }^{36}$. Tereo y Progne tienen además una hija, Héléna, de edad indefinida, aunque da la impresión, por su madurez, de que podría ser un poco mayor que su hermano Adis. Al círculo familiar se añade Léda, la anciana nodriza de Progne y Filomela, modelada quizás sobre la nodriza de Fedra en Séneca. Hay que mencionar, además, a dos pretendientes de Filomela, los príncipes Théagène e Ilion ${ }^{37}$, el pérfido Agoras,

${ }^{33}$ En lo sucesivo, y por comodidad, adaptamos -salvo en el caso de la cita literal de pasajes de la obra- los nombres de los cuatro personajes consagrados por el mito, que en Geschwin son Procné, Philomèle, Térée e Itys, a las formas usuales en la tradición española: Progne, Filomela, Tereo e Itis.

${ }^{34}$ Así, cuando Itaque, el comandante de la guardia, anuncia a Progne el inminente regreso de su esposo en la escena primera del segundo acto le explica que, a pesar de que vuelve enflaquecido y sombrío, su rostro se iluminó al oír el nombre de Itis, y formuló incluso el siguiente deseo: «Puisses-tu trouver mon dernier né grandi et vigoureux prononçant déjà le nom de son père» (Geschwin 1962, pp.22-23).

${ }^{35}$ En la escena séptima del acto primero, por ejemplo, lo vemos preocupado por la confianza que deposita Tereo en Agoras, enemigo jurado del padre de su esposa: «D’où peut naître, madame, l'insolent crédit dont jouit ce Mède éffronté, autrefois banni par le roi Pandion?» (Geschwin 1962, p.17).

${ }^{36}$ En la escena segunda del segundo acto, por ejemplo, cuando su hermana le pide que salga con ella al patio para socorrer a un pájaro herido, le replica que se ocupe ella de ese cuidado, porque él debe dirigirse «où m'appellent l'étude et la méditation, tutrices des futurs souverains» (Geschwin 1962, p.25).

${ }^{37}$ La figura del enamorado de Filomela aparece ya en algunas versiones españolas anteriores a la eclosión del tema de Tereo en la dramaturgia francesa, como las de Guillén de Castro (Teosindo) y Francisco Rojas Zorrilla (Hipólito), en las que el pretendiente es además hermano de Tereo, detalle este que quizás deba remitirse, en último término, a la versión del mitógrafo romano Higino, en la que se habla de un hermano de Tereo, Driante, a quien el tirano tracio hizo dar muerte malinterpretando un oráculo que le había predicho que la vida de su hijo corría peligro por las maquinaciones de alguien de su familia. La figura del pretendiente de Filomela aparece también en algunas versiones dramáticas francesas, aunque sin parentesco con Tereo, ya desde la influyente versión de Roy, donde se llama Athamas, como en Piron y Lemierre, mientras que en la de Renou se llama Iphidamas. En Geschwin, novedosamente, encontramos dos pretendientes que mantienen entre sí una sana rivalidad. 
consejero y hombre de confianza de Tereo, el honrado y fiel Euclès, comandante de la guardia de palacio, su lugarteniente Itaque, hombre también intachable ${ }^{38} \mathrm{y}$ apegado, como Euclès, a Progne, y el furibundo e implacable sacerdote Eléas, además de una serie de personajes colectivos y figurantes: oficiales, guardias, esclavos, artistas, el pueblo, sacerdotes...

El argumento en la versión de Geschwin es como sigue. Tereo, un rey guerrero, que acudió en su momento en ayuda de Pandión y casó después con su hija Progne, recién llegado de una de sus continuas expediciones militares, ahíto de vino y con el espíritu turbado por los excesos de la suntuosa fiesta con la que se celebra la victoria, viola, sin reconocerla inicialmente, a su cuñada Filomela, que vive en palacio con su hermana Progne; apenas una niña cuando partió a la guerra Tereo diez meses antes, se ha convertido en ese lapso de tiempo en una mujer deslumbrante, que ha rechazado durante la ausencia del rey a numerosos pretendientes ${ }^{39}$, dos de los cuales, Théagène e Ilion, viven incluso en palacio. Tereo, quizás por ese cambio físico que ha experimentado la muchacha durante su ausencia, y quizás también porque los acontecimientos tienen lugar en medio de una fragorosa tormenta, no ve en la mujer asustada y con el cabello y las ropas en desorden que le traen unos soldados borrachos más que otra de las prisioneras de guerra con las que suele saciar su lujuria en las orgías que acompañan sus regresos. Cuando al fin comprende lo que ha hecho, arrepentido y lleno de remordimientos, sale precipitadamente del palacio y encarga a su consejero Agoras, sin darle instrucciones específicas, que se ocupe de silenciar el asunto. El implacable Agoras, entonces, corta la lengua a la princesa y la encierra en un torreón.

La preocupación, entretanto, se adueña de Progne, porque Filomela no suele apenas apartarse de su lado, pero nadie la ha visto desde que estalló la tormenta, momentos antes de la cual reposaba adormecida en un banco en los jardines. Euclès, responsable de la seguridad del palacio, que la ha buscado en vano durante horas, después de haber sugerido que podría tratarse de un nuevo caso de rapto de una mujer hermosa por alguna divinidad, acaba quitándose la vida al no poder dar con el paradero de la muchacha. Progne, preocupada por esas palabras sacrílegas, encomienda a su hija Héléna que encargue al pontífice Eléas el sacrificio de cuantiosas víctimas, para aplacar la cólera divina y tratar, además, de descubrir, consultando las entrañas de los animales sacrificados, algún mensaje de los dioses que pueda arrojar luz sobre la desaparición de su hermana.

\footnotetext{
${ }^{38}$ La presencia de un consejero maduro de un rey aún relativamente joven e impulsivo es tópica en los dramas de temática comparable. Todas las versiones francesas anteriores cuentan con esta figura, casi siempre en la modalidad de consejero amoral que espolea en vez de refrenar en su lascivia al tirano tracio, pero solo la de Lemierre presenta esta misma dicotomía entre el consejero amoral y el sensato (Agoras y Euclès -y tras su muerte, Itaque- en Geschwin, y Olynte y Adraste en Lemierre).

39 Aunque no hay que ver en ello el indicio de una Filomela mundana o casquivana, como se desprende del recuerdo que Théagène comparte con Ilion en la segunda escena del tercer acto: «C'est ici que nous la vîmes pour la dernière fois. Elle filait aux pieds de la reine, et ses yeux chastement baissés n'osaient nous regarder de peur de marquer quelque préférence» (Geschwin 1962, p.41).
} 
Progne, en todo caso, no cree que pueda haber sido cosa de dioses, sino de hombres, y no piensa tampoco que se trate de una acción política o de bandidaje: solo un corazón enamorado se atrevería a tanto, y Filomela, en verdad, ha rechazado ya a muchos pretendientes, incluidos los dos que viven en el palacio, y están, por consiguiente, al tanto de los hábitos de la princesa. Tereo, sin embargo, según se informa a Progne, atribuye el rapto al rey de Tebas, que le paga así por la ayuda prestada antaño a Pandión, y se ha puesto en marcha al frente de sus tropas, encomendando a Agoras la defensa del reino. Se preparan, además, tropas de refuerzo para unirse al ejército de Tereo, a cuyo frente se ponen Théagène e Ilion, los dos pretendientes de Filomela.

Entretanto, el sacerdote Eléas informa a la reina del inquietante mensaje de los dioses: Filomela vive, pero ha sido forzada y mutilada, y permanece recluida, aunque no ha sido desvelado el nombre del malhechor. Sin embargo, podría ser que los dioses estuvieran irritados con Tereo por su comportamiento inicuo e implacable, en el que nunca han hecho mella las recriminaciones de Eléas. Quizás, ya hartos de las atrocidades cometidas o consentidas por Tereo, hayan permitido que ocurra todo esto para hacer que en lo sucesivo se refrene, o quizás el marido o el padre de alguna de tantas mujeres violadas o masacradas haya perpetrado esta abominación como retaliación o venganza. Progne, dando crédito a la hipótesis del sacerdote, que le insiste en que debe enviar un mensaje inequívoco a Tereo, pronostica, furiosa, el sufrimiento de su esposo cuando regrese y vea el cuerpo desmembrado de su más querido hijo, y más aún cuando sepa que ha sido muerto por orden de su esposa.

Con ello concluye el primer acto, centrado en la figura de Progne, que no abandona nunca la escena sino que, sucesivamente, se enfrenta o se entrevista con sus hijos (escenas I, III y VII), el capitán de la guardia Euclès (escena II), el consejero Agoras, Itaque y los dos pretendientes (escenas V y VI) y el pontífice Eléas y su séquito de sacerdotes (escena IX). Además, queda sola en escena en dos ocasiones, que le permiten desnudar su alma ante los espectadores (escenas IV y VIII). La acción comienza in medias res, en el momento en que Progne, angustiada por la desaparición de su hermana, despacha a sus hijos en busca de Euclès, por lo que la violación, glosotomía y encierro han ocurrido, en rigor, antes de que la tragedia dé comienzo.

El segundo acto empieza con una comida familiar de Progne con sus hijos y su nodriza, interrumpida por la llegada de Itaque, que informa de que Tereo se ha cubierto de gloria en la guerra, pero no ha logrado dar con Filomela. Regresa cambiado, enflaquecido y más sombrío de lo habitual y le ha ordenado que anuncie su inminente llegada y se ocupe de preparar un festín para sus oficiales. A continuación tiene lugar el desvelamiento del violador de Filomela, al reparar Héléna en que los pajarillos, a los que tanto amaba Filomela, no abandonan desde hace un mes las almenas de la torre y uno de ellos se arrastra penosamente, con un mensaje enrollado en sus frágiles patas con el nombre de la reina. Al leerlo, Progne descubre que el verdugo de su hermana es Tereo. Tras recobrar la conciencia, trata de quitarse la vida, pero la nodriza se lo impide, y Progne acaba revelando el juramento que, irreflexivamente, había hecho a los dioses. Léda la insta a que ruegue al cielo que olvide unas palabras pronunciadas con un exceso de vehemencia y sugiere privar a Tereo de sus hijos sin 
llegar a esos extremos, huyendo con ellos a Atenas para acogerse a la protección de su hermano Erecteo. Progne se niega a escapar, para no abandonar a su suerte a Filomela, pero consiente en permitir la huida de sus hijos, que podría encomendarse al fiel Itaque. La nodriza parte en su busca, con el encargo de avisar también a Eléas, el único que podría tranquilizar a la reina sobre las consecuencias del incumplimiento de su juramento.

Llega primero Itaque, que hace ver a la reina que intentar liberar a Filomela con solo algunos soldados, por lo demás exhaustos, sería pura locura: es más sensato esperar a la celebración del festín, cuando los espíritus estén ofuscados por el vino. Acuerdan, pues, que Adis y Héléna partan inmediatamente a caballo, como para dar un paseo, mientras que Itaque tratará de sacar de palacio a Itis cubierto por un manto.

La situación se complica con la llegada de Eléas, que recrimina a Progne su resistencia a cumplir su juramento, incluso una vez que ha quedado claro que es su esposo el culpable de tan crueles hechos. Si quiere salvar a sus otros hijos, no tiene otro remedio que sacrificar a Itis; tal es el decreto de Zeus ${ }^{40}$. Progne se niega a creerlo, pero entra entonces, moribundo, Adis, que informa de que un mal misterioso se ha apoderado de los tres hermanos y pide a su madre que lo salve. Léda la insta a que salve a sus hijos, a lo que la reina replica que, muertos, ya no sufrirán, y se verán libres de la guerra, el oprobio y la locura. Léda le insiste en que tenga piedad y ordene la muerte de Itis, pero Progne no atiende a razones, con lo que Eléas dictamina que ha perdido el juicio y ordena que se la lleven. Y, dirigiéndose a la nodriza, le dice estas ominosas palabras, con las que termina el acto: «Et toi, femme, tu l'as entendue. Prends ce couteau. Va sauver ses enfants en assurant la vengeance des dieux!» (Geschwin 1962, p.36).

La figura central en este segundo acto continúa siendo Progne, que se enfrenta o dialoga a lo largo de él con su familia, con su nodriza, con el fiel Itaque y con el implacable sacerdote Eléas, que domina con su presencia inquietante la última escena de cada uno de los dos primeros actos, forzando, en el primero, a Progne a formular el terrible juramento, y ordenando a la nodriza, al final del segundo, su ejecución, en vista de la enajenación de la reina.

En el tercer acto comparece al fin Tereo, al que vemos preocupado por el informe que le da Agoras sobre su familia - el adivino Eléas y los médicos han decidido aislar a Progne en el templo de Zeus ${ }^{41}$ y enviar a los niños al palacio de Polygoros en la Calcídica-, pero aún más por el paradero de Filomela. Agoras le hace saber que está encerrada en la torre y que esa proximidad no supone peligro alguno, porque la muchacha es ahora muda. Tereo, presa de los remordimientos, le confiesa que habría

\footnotetext{
${ }^{40}$ El sacerdote, por tanto, plantea a Progne un auténtico dilema trágico: si quiere salvar a Adis y Héléna, debe sacrificar a Itis, pero si no lo hace, morirán los tres. Un dilema, por cierto, no muy distinto del que se plantea, en la cultura de masas de nuestro tiempo, a la protagonista de la película La decisión de Sophie (Sophie's Choice, Alan J. Pakula, 1982).

${ }^{41} \mathrm{La}$ idea de que Progne se refugie en un templo estaba ya en la versión de Roy-Lacoste, en la que la sacerdotisa Cleone le aconseja que se refugie en el templo de Himen, después de haber tenido una violenta discusión con su esposo. Cf. Martín Rodríguez (2009, p.11).
} 
preferido no volver nunca, porque todo en su palacio le reprocha su crimen, y no sabe con qué cara volver a presentarse ante los suyos ${ }^{42}$. Ha perdido el sueño, ha perdido también la tranquilidad y la soberbia de los hijos de dioses y sus noches están pobladas de horribles pesadillas que renuevan en su espíritu los horrores inevitables de guerras sin embargo gloriosas: la desleal Tebas entregada al saqueo y ahogada en la sangre de sus habitantes, las llamas devoradoras de Larissa reflejadas por las nieves del Pelión, la impúdica juventud de Drama y de Sères marcada en su carne como vil ganado y abandonada miserable sobre las orillas del lago Tachino ${ }^{43} \ldots$ todas las violencias, las orgías y los gritos que ha acallado con el ruido de su gloria y de su ilustre nombre. Y eso por no hablar de esa desdichada que gime en la torre sombría, lo que le da pie para contar con detalle a Agoras cómo ocurrió todo, del modo en que hemos explicado más arriba. El malvado consejero, por su parte, trata de tranquilizarlo, inculpando a los dioses, que le dan tal recompensa por sus victorias y sus esfuerzos, censurando a la propia Filomela por no haber pensado en sacar partido de aquel lamentable error en vez de abismarse en la desesperación y recordándole, en fin, que en la guerra y los placeres uno solo debe ser fiel a sí mismo. Tereo, más aliviado, le pide que la aleje de allí y que no le vuelva a hablar nunca más del asunto.

Ya en el banquete, la nodriza, calzando el coturno y portando la máscara de los actores trágicos, revela la verdad a los invitados de Tereo, que ordena que la apresen, pero Ilion y Théagène la defienden y la intiman a que siga hablando. Se arranca, entonces, la máscara y anuncia a Tereo que Itis, su hijo favorito, ha muerto, apuñalado en su cuna por orden de la reina y que es su carne lo que ha engullido. Tereo despacha a Agoras al templo para hacer expiar a la reina su crimen, mientras estalla una pavorosa tormenta y se desencadena un combate generalizado en el que Tereo, invulnerable, da muerte a los pretendientes y a cuantos se le oponen, hasta quedar rodeado de cadáveres. Finalmente, un rayo lo abate, aunque sin darle muerte.

Regresa, entre tanto, Agoras y confirma a Tereo que su hijo ha sido vengado, pero es preciso huir de la cólera del pueblo. El ejército se ha dividido, mercenarios y patriotas se enfrentan en combates callejeros, que han dejado las calles cubiertas de cadáveres, y solo esto los protege aún de la ira del populacho: todavía hay tiempo de huir... Pero Tereo quiere saber con detalle lo ocurrido y Agoras se lo explica: con algunos soldados fieles voló al templo de Zeus, donde Filomela, liberada por Itaque, se había reunido con Progne. Mientras se libraba un rápido combate en el que se impusieron los partidarios de Tereo, las dos hermanas lograron escapar y en una carrera desenfrenada llegaron, cogidas de la mano, a lo alto de una pequeña loma coronada de pinos secos. Allí, acosadas por todas partes, desaparecieron en lo hondo de un inextricable bosquecillo. Siguiendo sus órdenes, una llama inmensa lo devoró todo

\footnotetext{
42 Una notable inversión con respecto al Tereo ovidiano, que no siente empacho alguno en presentarse tras la violación ante Progne para informarla con lágrimas de cocodrilo sobre la supuesta muerte de su hermana: Sustinet ad Prognen post talia facta reuerti (Ov.Met.6.563).

${ }^{43}$ Se refiere, probablemente, a las actuales regiones de Serres y Drama en las zonas central y oriental de la Macedonia griega, respectivamente. El lago Tachino se encuentra en la primera de dichas regiones.
} 
en unos instantes, aunque ninguna queja, ningún grito se elevó del infernal brasero; simplemente, dos pájaros salieron de allí, un ruiseñor y una golondrina, y los rozaron con sus alas antes de desaparecer en la noche. Tereo, entonces, renuncia a la huida, dispuesto a expiar sus crímenes junto con Ágoras, y el pueblo amotinado entra por todas partes y acribilla sus cuerpos con mil heridas.

El acto tercero, como se ve, es el acto de Tereo, presente en casi todas las escenas, mientras que Progne ha abandonado ya el escenario, y comparece solo indirectamente en los relatos de Léda y de Agoras.

Nos toca ahora reflexionar sobre los cambios operados en la tragedia con respecto a la versión canónica. Dejando aparte los referidos a la inclusión de nuevos personajes, detallados más arriba, los más notables son los siguientes:

- Mientras que en Ovidio Filomela vive aún en Atenas con su padre Pandión, en la versión de Geschwin Pandión ha muerto y en Atenas ya reina su hijo Erecteo, mientras que Filomela, aún casi una niña, ha sido acogida por Progne en Tracia, para quien es menos una hermana que una hija.

- En Ovidio, Tereo se enamora de Filomela al conocerla en Atenas, disimula su pasión - para conseguir el permiso paterno- $y$, de camino a Tracia, tras revelarle en vano su pasión, la viola, le arranca la lengua y la encierra, diciéndole a Progne que había muerto durante la travesía. En Geschwin, Tereo, al regresar de una de sus victoriosas campañas, acostumbrado a las violencias con las prisioneras en las celebraciones de sus victorias, viola a su cuñada sin reconocerla, y, cuando lo hace, huye despavorido. Es Agoras quien le corta la lengua y la encierra, mientras Tereo, con la excusa de rescatar a Filomela, parte con su ejército en busca de nuevas guerras. En ningún momento, y es la única versión dramática de la leyenda en la que esto ocurre, coinciden en escena Progne y Tereo. Las informaciones sobre la desaparición -y no muerte- de Filomela corren aquí a cargo del fiel Euclès, y no de Tereo.

- En Ovidio, Filomela se las ingenia para ponerse en contacto con su hermana y revelarle lo ocurrido por medio de una tela bordada que le hacer llegar por medio de una criada. En Geschwin, la anagnorisis se produce en dos tiempos: primero, el sacerdote Eléas, inspeccionando las entrañas de las víctimas, se entera de que Filomela está viva, pero recluida y con la lengua cortada, aunque no alcanza a saber ni su paradero ni el nombre del culpable; después, por medio de un mensaje atado a la pata de un pichón, Filomela hace saber a su hermana que se encuentra en la torre, y que su verdugo es Tereo.

- En Ovidio, Progne aprovecha las fiestas de Baco para liberar, disfrazada de bacante, a Filomela, e introducirla subrepticiamente en palacio, donde ambas dan muerte al niño Itis y lo sirven a la mesa a su padre. En Geschwin, Progne no puede ocuparse personalmente de la liberación de Filomela, porque ha sido confinada en el templo de Zeus. Es el fiel Itaque quien aprovecha el festín para liberarla y llevarla al templo junto a su hermana. Las dos atenienses, por tanto, no pueden, como en Ovidio, dar muerte al niño, tarea que ejecuta la nodriza; según le dice a Tereo, para mortificarlo, por orden de la reina, pero, según 
queda claro al final del segundo acto, siguiendo, en realidad, las instrucciones de Eléas. La carne del niño, como en Ovidio, le es servida al padre, aunque da la impresión de que se trata de lo que bien podríamos llamar, con el lenguaje de nuestros días, un «fallo de raccord», porque en el juramento pronunciado irreflexivamente por Progne en el primer acto se hablaba de matar al niño, pero no de servir su carne a Tereo.

- En Ovidio, son Progne y Filomela quienes hacen saber a Tereo de la muerte de su hijo; Progne, diciéndole enigmáticamente que el niño al que busca está dentro ${ }^{44}$, y Filomela, arrojándole a la cara la cabeza del crío. En Geschwin, al no asistir las dos atenienses al festín, esta tarea corresponde también a la nodriza.

- En Ovidio, Tereo, al saber la verdad, trata de dar muerte a las hermanas, que escapan de él convirtiéndose en aves. En Geschwin, Agoras, por orden de Tereo, se dirige al templo para matar a Progne, pero las dos se refugian en un bosquecillo, al que prende fuego el desalmado Agoras, de cuyas llamas escaparán un ruiseñor y una golondrina, las aves en las que la tradición cuenta que se convirtieron las dos princesas atenienses.

- En Ovidio, Tereo se metamorfosea en abubilla. En Geschwin, muere como consecuencia de un motín, del que rehúsa escapar, para expiar sus culpas junto al malvado Agoras ${ }^{45}$.

Parece evidente, después de nuestro análisis, que el dramaturgo francés conocía bien el mito de Filomela, sin que ello fuera óbice, naturalmente, para que lo sometiera a las transformaciones argumentales que estimó oportunas para la consecución de los objetivos artísticos que tenía en mente. Ese conocimiento pudo venirle a través de cualquier repertorio mitológico, aunque tenemos la impresión de que pudo también tener cierta familiaridad con la versión ovidiana. Es verdad que una interpretación demasiado restrictiva de lo que dice Geschwin en el colofón que coloca al final del texto podría apuntar a un desconocimiento palmario de la tradición literaria del mito: «Le sujet de cette tragédie est la légende célèbre de Philomèle et de Procné, rendue plus supportable, et tournée contre la guerre elle-même. Elle avait, paraît-il, inspiré Sophocle dont la Tragédie intitulée Térée s'est perdue pour toujours» (Geschwin 1962, p.48). Pero la intención del autor al escribir estas palabras creemos que es muy

\footnotetext{
44 intus habes, quem poscis (Ov.Met.6.655), son las palabras de Progne, donde intus, ominosamente, significa 'dentro de ti', porque Tereo ha engullido ya la carne de su hijo, aunque el rey interpreta que lo que ha querido decir su esposa es 'dentro de la sala del banquete'; de ahí la acción de mirar a su alrededor de que se habla a continuación: Circumspicit ille / atque, ubi sit, quaerit (ib.6.655-656).

${ }^{45} \mathrm{La}$ muerte de Tereo es usual en las versiones dramáticas francesas que nos han 1legado, aunque solo aquí muere a manos del pueblo amotinado. En la versión de Roy, se suicida tras no conseguir atrapar a las dos hermanas; en Guys, tras ver los cadáveres de su esposa y su hijo; en Pijon, tras conocer la muerte de su hijo; en Lemierre, con su propio puñal, presa del delirio; en Renou, trata también de suicidarse, aunque no lo consigue, y en un final alternativo que el autor propone se arrepiente de sus crímenes, renuncia al trono y marcha errante, como un alma en pena, de país en país. En la parodia de Piron, como era de esperar, no deja de sacarse jugo cómico a las intenciones suicidas del tirano: renunciado a su primera intención de clavarse un puñal, se inclina finalmente por acabar con su vida mediante un atracón de vino.
} 
otra, y que lo que quiere decirse más bien es que, aunque todo el mundo conoce esta historia a partir de las Metamorfosis, la primera versión canónica en la antigüedad clásica fue también una tragedia, por lo que nada de raro tendría que también ahora se recurriera para volver a contarla al molde dramático ${ }^{46}$, aunque ajustándolo, eso sí, al espíritu de la época; esto es, dulcificando un poco los horrores de la trama canónica y dotándola de una nueva intención acorde con las preocupaciones de la Francia del momento.

Sin embargo, algunos detalles de la tragedia apuntan, directa o indirectamente, al texto ovidiano; tomados de manera individual, podrían parecer simples coincidencias, pero, vistos en su conjunto, no dejan de tener su peso. En las palabras de Progne, sorprendida de que los dioses informen sobre la situación de Filomela, pero callen su paradero y no hayan hecho siquiera un esfuerzo por protegerla, podría haber, por una parte, un recuerdo de las súplicas vanas de Filomela en Ovidio antes de la violación y por otra, de los sólidos muros que después la enclaustran ${ }^{47}$; la exhortación de Léda a Progne para que -en un extraño acto de piedad- dé muerte a Itis, único modo de salvar la vida de sus otros dos hijos, recuerda al comentario de la Progne ovidiana de que, estando casada con Tereo, el crimen equivale a un acto de pietas ${ }^{48}$; la acción de derribar la mesa los pretendientes en medio del festín cuando se descubren los crímenes del tirano recuerda a la acción similar del Tereo ovidiano cuando descubre que ha ingerido la carne de su hijo ${ }^{49}$; el momento en que Tereo, en medio del banquete, tilda de Furia a la nodriza, hace pensar en la invocación a las Euménides del Tereo ovidiano en el momento equivalente de la trama ${ }^{50}$; los mil golpes con los que el pueblo amotinado acribilla el cuerpo de Tereo parecen reminiscentes de las mil heridas por las que desearía arrancarle el alma la Progne ovidiana ${ }^{51}$; la mención de Erecteo, hijo de Pandión y hermano de Progne y Filomela, como rey de Atenas, podría ser un eco de lo que se dice en las Metamorfosis, inmediatamente después del final de la historia, cuando las luctuosas noticias llegan al Ática ${ }^{52}$; y la misma indeterminación

${ }^{46}$ Recuérdese que habían ya transcurrido casi dos siglos desde que Tereo había subido por última vez a los escenarios franceses.

${ }^{47}$ «Dans son supplice, elle a pu implorer le Ciel sans émouvoir les dieux! ces dieux attentifs qui se hâtent pourtant d'annoncer le crime! Comment comprendre? Un mur! un mur d'airain se dresse devant ma raison» (Geschwin 1962, p.20). Cf. Ov.Met.6.525-526: ui superat frustra clamato saepe parente, / saepe sorore sua, magnis super omnia diuis, y 573: structa rigent solido stabulorum moenia saxo, aunque en la tragedia francesa el muro se presenta como un obstáculo para Progne, no para Filomela.

48 «Vous n'avez pas le droit!... Je vous en conjure, revenez à vous; ayez pitié, et ordonnez d'Ytis! Il le faut» (Geschwin 1962, p.36). Cf. Ov.Met.6.635: Scelus est pietas in coniuge Tereo.

${ }^{49}$ En acotación, en efecto, se señala: «Ilion et Théagène renversent alors la table...» (Geschwin 1962, p.45). Cf. Ov.Met.6.661: Thracius ingenti mensas clamore repellit.

${ }_{50}$ «Horreur! Horreur! O crime! O paroles inexpiables! Ah! Furie!...» (Geschwin 1962, p.46). Cf. Ov.Met.6.662: uipereasque ciet Stygia de ualle sorores.

${ }^{51} \mathrm{Cf}$. la acotación de la escena III.7: «Un peuple résolu entre de tous côtés et, silencieux, les perce de mille coups» (Geschwin 1962, p.48), y Ov.Met.6.617-618: aut per uulnera mille / sontem animam expellam.

52 «Retournez avec eux dans Athènes où leur oncle Erechtée les prendra sous sa protection» (Geschwin 1962, p.30). Cf. Ov.Met.6.675-677: Hic dolor ante diem longaeque extrema senectae / tempora Tartareas Pandiona misit ad umbras; / sceptra loci rerumque capit moderamen Erechteus. 
acerca de en qué ave se convierte cada una de las princesas atenienses encontramos en las dos obras, aunque Ovidio ofrece algunas pistas indirectas que faltan al lector de la tragedia francesa ${ }^{53}$.

\subsection{INTENCIÓN Y SENTIDO DE LA TRAGEDIA}

Hay que recordar, en primer lugar, que Geschwin intentó, como él mismo reconoce, dulcificar un poco las atrocidades de la historia primigenia ${ }^{54}$, exculpando de alguna manera, aunque solo fuera parcialmente, a los protagonistas. Así,

- Tereo, en Ovidio un villano cumplido, marido falsario, que no tiene reparos en engañar a su suegro para que permita el viaje de Filomela, se le declara sin tapujos una vez ya fuera de Atenas, la viola (quizás de modo repetido ${ }^{55}$ ), le amputa la lengua, la encierra y tiene incluso el descaro de comparecer ante su esposa bañado en falsas lágrimas para darle cuenta de la supuesta muerte de su hermana, es también en Geschwin violador de su cuñada, pero con la atenuante de no saber que se trata de ella, y enseguida se horroriza y decide abandonar de nuevo Tracia sin ver siquiera a su esposa. No es, por tanto, el autor de la glosotomía ni del encierro, y tampoco tiene la hipocresía de comparecer ante Progne. Ama, además, a sus hijos, sobre todo al pequeño Itis ${ }^{56}$, y es presa de los remordimientos por lo sucedido con Filomela. Solo al enterarse de la muerte de Itis se desencadena en él contra su esposa la furia de un monstruo, aunque al final renuncia a huir y prefiere pagar sus culpas con su vida.

- Progne se resiste a dar muerte a Itis, a pesar de su juramento, que no puede finalmente cumplir, pues cae víctima de un paroxismo nervioso, y es Eléas quien ordena a la nodriza que dé muerte al niño, mientras Progne permanece confinada en el templo de Zeus.

- Filomela no participa tampoco, como en Ovidio, en la muerte del niño, sino

53 «Et nous restions là, haletants et stupéfaits, lorsque deux oiseaux en jaillirent, comme projetés par les dernières flammes. C'étaient un rossignol et une hirondelle qui nous frôlèrent, avant de disparaître dans la nuit!...», se dice, simplemente, en el drama de Geschwin (1962, p.48), mientras que Ovidio indica que una de ellas se marcha a los bosques, mientras que la otra vuela a los tejados, con su pecho aún manchado por la sangre, indicaciones que la crítica suele interpretar en el sentido de que una (Filomela) se convierte en ruiseñor y se marcha a los campos, escenario habitual del incesante canto de dicho pájaro, y la otra, la madre asesina, se convierte en golondrina, ave que anida en los aleros y tiene, en su variedad más común, una mancha parduzca en el buche; cf. Ov.Met.6.668-670: Quarum petit altera siluas, / altera tecta subit; neque adhuc de pectore caedis / excessere notae, signataque sanguine pluma est.

${ }^{54}$ Es curioso que ya Pierre-Charles Roy, el autor del texto de la primera versión dramática francesa conservada, se sintiera obligado a incluir lo siguiente en un Avertissement: «Il falloit adoucir des caracteres odieux, ôter des incidents qui auroient blessé la bienséance \& la pureté du Theâtre, \& en substituer de plus convenables»; cf. Martín Rodríguez (2009, p.9, n.21).

${ }^{55}$ Cf. el empleo significativo de saepe en Ov.Met.6.561-562: Hoc quoque post facinus (uix ausim credere) fertur / saepe sua lacerum repetisse libidine corpus.

56 «Chers enfants! Cher Itys! dès demain, on me verra tout quitter pour vous serrer dans mes bras», lo oímos decir, por ejemplo, en la primera escena del tercer acto (Geschwin 1962, p.37). 
que es aquí simple y totalmente una víctima: es violada, le arrancan la lengua, la encierran, es liberada y llevada al asilo de un templo, de donde tiene que huir para refugiarse en un bosque que es finalmente incendiado, y de donde solo puede salir ya metamorfoseada en ave.

Pero, como el propio autor señala, su intención es también la de hacer un alegato contra la barbarie de esa guerra endémica que parece haberse incardinado en Francia. Las referencias a las atrocidades de la guerra son, en efecto, constantes, y en algunos casos parecen poder detectarse alusiones veladas a situaciones que hacen pensar en la propia realidad de las guerras de ultramar francesas.

Ya al comienzo de la tragedia vemos a Progne con el pequeño Itis en sus brazos, pidiendo a los dioses que lo mantengan siempre alejado de las luchas homicidas que ocupan hasta la hora de la muerte las almas de los guerreros (Geschwin 1962, p.9). Después, mientras espera la llegada del sacerdote Eléas, reflexiona sobre cómo la desgracia, en forma de guerra perpetua, parece haberse aposentado en su casa. El propio Eléas, tras informarla del resultado de la consulta de las entrañas de las víctimas, le transmite su convicción de que los dioses están irritados con Tracia por el comportamiento atroz -con la connivencia criminal de su jefe-de las tropas de Tereo, a quienes se define en su mayor parte como mercenarios reclutados de entre los bár$\operatorname{baros}^{57}$, fieras sedientas de sangre que no encuentran reposo sino en la borrachera, el pillaje y el horror, a quienes se ha acogido como a hijos, pero siguen siendo esclavos de sus instintos, e incapaces, incluso en Tracia, de respetar a viejos, mujeres ni niños. Y de nada han valido las denuncias que el propio Eléas ha presentado ante Tereo, que se cierra en banda y entiende que estas críticas no hacen otra cosa que rebajar el buen nombre de su ejército, y a través de él a la patria y a su monarca divino. La crítica de las atrocidades cometidas por un ejército en que se integran importantes efectivos de soldados procedentes de las colonias y que no siente empacho en sembrar a su paso el terror, y la tendencia de las autoridades a entender que cualquier crítica en guerra contra las propias fuerzas es un ataque a la patria no puede ser más evidente ${ }^{58}$. Como también lo es la equivalencia entre Eléas y sus sacerdotes y la intelectualidad que tiene el deber de denunciar los abusos y mover las mentes de los ciudadanos para tratar de acabar con la injusticia.

\footnotetext{
${ }^{57}$ Debe recordarse que en la sangrienta guerra de independencia de Argelia los nacionalistas del FLN no hubieron de enfrentarse solo a las tropas regulares francesas, sino también a los llamados harkis, contingentes militares de extracción local.

58 «Fils trop zélé du dieu des combats, Térée a porté la guerre dans des contrées de douceur et de lumière, et jusqu'au berceau même des arts et de la sagesse! Tout éprouve la rage de ses soldats, pour la plupart des mercenaires recrutés parmi les barbares ou chez les vaincus: fauves altérés de sang et de larmes qui ne trouvent le repos el l'oubli que dans l'ivresse, le pillage et l'horreur! Même revenus parmi nous, accueillis comme nos propres fils, ils restent asservis aux pires instincts. On se terre sur leur passage! Les temples retentissent des cris et des plaintes des vieillards molestés, des femmes et des enfants meurtris!... Vingt fois, je suis venu moi-même en ces lieux éclairer votre époux, plaider la sainte cause de l'innocence. Il ne voit rien ou excuse tout! Que dis-je? Il s'irrite à ces justes accusations: on outrage, on ravale sa glorieuse armée, et à travers elle la patrie et son monarque divin!...» (Geschwin 1962, p.21).
} 
Pero no es solo que las tropas tracias integradas mayoritariamente por soldados no tracios puedan cometer todo tipo de atrocidades; es que, además, pueden provocar, por parte de sus víctimas, un movimiento de retaliación ${ }^{59}$ : así, quizás el rapto, la violación y la mutilación de Filomela no sean solo un aviso de los cielos, sino una represalia por hechos semejantes cometidos contra la esposa, la hermana o la hija de algunos de los vencidos y humillados por Tereo. Y que no se trata solo de exageraciones de los siempre quisquillosos intelectuales lo prueba el diálogo, poco antes del festín en torno al que se centra el acto tercero, entre los pretendientes Théagène e Ilion, que se embarcaron en la empresa guerrera de Tereo para liberar a Filomela (esto es, creyendo que se enrolan en una guerra justa), pero regresan desengañados y escarmentados por las atrocidades que han vivido: al verlo ceñir sus armas, se estremecieron primero de esperanza y de entusiasmo juvenil, creían que iban a vivir una epopeya digna de Homero. Pero jamás huracán alguno partido del Danubio fue más cruel y más devastador que la rabia contagiosa de Tereo: ante la mirada indignada del Olimpo, todo fue para él pretexto para masacres, incendios y torturas, y se diría incluso que sentía un placer secreto al ver a sus soldados deshonrarse por la violación y el asesinato. De modo que vuelven ahora avergonzados y desengañados, y firmemente decididos a hacer lo que sea preciso para prevenir nuevas guerras.

Pero no solo la guerra ha cambiado y ennegrecido a estos jóvenes idealistas que partieron creyéndose héroes: el propio Tereo, como confiesa a Agoras en III.1, ha perdido el sueño y la tranquilidad, y sus noches están pobladas de horribles pesadillas que vuelven a trazar ante sus ojos el horror de la guerra.

Se plantea también el tema de la responsabilidad colectiva. Cuando se producen estos atropellos, no solo el que está al frente de las tropas es el culpable. Es lo que han comprendido, ya de regreso de la guerra, los jóvenes pretendientes, y en concreto Théagène, que confiesa no haber pensado en otra cosa durante la guerra que en Filomela, sin caer en la cuenta de que con su silencio ante las atrocidades estaba aprobando los excesos que se estaban cometiendo. Y también se lo hará comprender Eléas a Progne, a quien encontramos, antes de la primera visita del sacerdote, tratando de entender por qué la desdicha parece haberse aposentado en su casa, cuando su conducta hasta ahora ha sido intachable. ¿No es una esposa modesta, una tierna hermana, una madre querida, que no ha dejado que la ortiga y las malas hierbas invadan el acceso a los altares ni que las lechuzas se aposenten en las cornisas de los templos, ni que los indigentes mueran de hambre a las puertas del palacio? Pero Eléas la saca pronto de su engaño: es a ella, como representación de la sociedad que no participa en las atrocidades, pero las convalida con su silencio, a quien le toca desenmascarar a un canalla que insulta a la naturaleza humana e infligirle el

\footnotetext{
${ }^{59}$ La guerra de Argelia se caracterizó, en efecto, por una extrema brutalidad, tanto por parte de las tropas francesas, que no retrocedieron ante la violencia contra civiles y la tortura, como de los insurgentes, que se emplearon a fondo en una guerra de guerrillas y en actividades terroristas cuyo blanco preferido fue la población francesa y los colaboracionistas, terrorismo, por cierto, en el que no le fue a la zaga la organización paramilitar en que se encuadraron los más virulentos partidarios de una Argelia francesa, la temible OAS. El año más virulento de la guerra, según se dice, fue precisamente 1962.
} 
castigo que merece para espantar para siempre a quienes puedan sentirse tentados de imitarlo. Y para ello hay que tomar medidas dolorosas, como veremos más claro en la segunda entrevista con Eléas, cuando, descubierta ya la culpabilidad de Tereo, Progne pretende todavía hallar algún modo de disculparlo ${ }^{60}$, y se resiste, en todo caso, a dar muerte a Itis, como había jurado: para salvar a Adis y a Héléna, tiene que permitir que Itis muera. Progne es, pues, la representación de la patria, y para salvar al menos a una parte de sus hijos tiene que consentir el sacrificio de otra parte ${ }^{61}$. No es posible lavarse las manos.

También se critica el mecanismo perverso del belicismo, que empieza, en muchos casos, en el terreno de la guerra justa, pasa enseguida al de la guerra por la guerra y la guerra por motivos espurios, y termina, finalmente, con la guerra civil. Es lo que ocurre con Tereo, que ayudó años atrás a un Pandión en apuros, se embarcó después en guerras cuyos motivos ignoramos, y al que vemos finalmente declarando una serie de guerras con el pretexto de rescatar a Filomela, cuando Filomela, en realidad, nunca había sido raptada, y se encontraba, de hecho, prisionera en la torre de su palacio. A su regreso, celebrando apenas con sus oficiales la victoria, está ya planeando nuevas expediciones. Pero el belicismo de Tereo, una vez que queda de manifiesto la sinrazón de sus razones y la atrocidad de su comportamiento, deriva en el cataclismo de una guerra civil, que afecta primero a su familia, en la que un cuñado ha violado a una cuñada, una esposa ha provocado la muerte del hijo para castigar al marido, el marido ha ordenado la muerte de la esposa... y después a la ciudad entera: al conocerse las atrocidades de Tereo, se produce primero un feroz combate en el salón del banquete, en que mueren todos salvo el tirano; a continuación, un enfrentamiento en el templo de Zeus entre los defensores de la reina y los partidarios de Tereo; después, una batalla campal en las calles, sembradas ya de cadáveres, entre los mercenarios que apoyan al rey y los verdaderos patriotas, que se le oponen; y por último, el pueblo entero se alza en armas y acaba con su soberano.

Si concebimos, en fin, la trama mitológica de la obra como una alegoría, el mensaje de fondo bien podría ser el siguiente: la barbarie engendra barbarie. Si uno se habitúa, en un rosario continuo de guerras fuera de la patria, a la comisión sin freno ni remordimiento de atrocidades contra víctimas -indefensas o no- de países ajenos, se desliza por una pendiente en la que, sin darse cuenta, puede acabar cometiendo esas tremendas tropelías contra su propio pueblo, representado simbólicamente en el drama por la propia familia. Y, cuando eso ocurre, de nada sirve tratar de silenciar a las víctimas encerrándolas o -más o menos metafóricamente- cortándoles la lengua: la verdad acaba saliendo a la luz y la indignación del pueblo puede llegar a una au-

\footnotetext{
60 «Non, ce n’est pas possible! Je connais Térée: C'est un rude soldat; mais il n’a pu... Tu vois comme je l'aimais, comme je l'aime encore!... Nous sommes la faiblesse même... Nous caresserions la main qui nous trahit et nous assassine!... Insensée que je suis! Je cherche! Je cherche encore!... Mais quelle excuse lui trouver?... Monstre! C'est un monstre que la guerre m'a rendu!...» (Geschwin 1962, p.28).

${ }^{61}$ Con la guerra de Argelia como telón de fondo, la cosa está aún más clara: para que Francia siga en pie, ¿no merece la pena renunciar a alguno de sus hijos? Esto es, no queda más remedio que consentir en la independencia de la colonia, que muchos consideraban parte inalienable de Francia.
} 
téntica guerra civil, que podría no detenerse siquiera en los umbrales nefandos del parricidio o incluso del magnicidio.

\section{CONCLUSIÓN}

A pesar de que se trata de una obra muy bien escrita y con un rico subtexto que hace de ella mucho más que el mero ejercicio de un diletante, parece evidente que $L e$ serment de Procné difícilmente podría encontrar un hueco entre las grandes obras de la literatura, lo que no excluye que tenga su interés para el estudioso de la tradición clásica. Lo que falla en la obra -dejando aparte juicios de calidad que en un análisis de estas características son cuestiones de menor relevancia- no es ni su interés por un tema, el de la guerra en general, y el de la sangrienta guerra de Argelia en particular, que era, desde luego de la máxima actualidad y sería abordado por otros dramaturgos de posguerra, ni el recurso a la mitología como clave alegórica para explorar el problema de la espiral belicista que arrastra ineluctablemente a los grandes conflictos, para lo que contaba con muy ilustres precedentes, sino lo que bien podríamos llamar una cuestión de timing.

Como ha señalado Brunel (2002, p.193), si la política es la vida de la ciudad, el teatro es sin duda la más apropiada de todas las artes para dar cuenta de ella. La preocupación por la política, por tanto, como no podía ser menos, además, en un país fuertemente influido en aquellos años por la dramaturgia brechtiana, no está en absoluto ausente de los intereses de los autores teatrales franceses de los años cincuenta. Las nuevas dramaturgias, con todo, aun sin renunciar necesariamente al subtexto político y polémico, encontrarían pronto el modo de evitar la trampa del teatro dogmático y militante, recurriendo a procedimientos y técnicas nuevos y originales. Eugène Ionesco, por ejemplo, presentó en Rhinocéros (1958) una original alegoría satírica de los movimientos de masas que acaban desembocando en los totalitarismos, y un empleo no menos original de la fábula política encontramos en Le ping-pong (1955), de Arthur Adamov. Y, en un contexto histórico en el que, como señalan Banquart y Cahné, «Après avoir connu une position dominante dans le monde littéraire, la France de la fin de la IVe République s'abîme dans des guerres perdues et vit l'effacement de ses grands intellectuels» (1992, p.379), sería sorprendente que la guerra -en potencia o real- hubiera estado ausente de las preocupaciones de los dramaturgos; así, Henri Pichette aborda, en plena Guerra Fría, el riesgo de una conflagración nuclear en $\mathrm{Nu}$ cléa (1952); la guerra de Corea inspira a Roger Vailland (Le colonel Foster plaidera coupable,1950) y a Michel Vinaver (Les Coréens, 1956), y la guerra de Argelia al propio Vinaver (Les Huissiers, 1958) o a Jean Genet (Les Paravents, 1961), además de a nuestro Geschwin.

Lo que sorprende, por tanto, no es que Geschwin escriba tragedias sobre la historia de Francia o una alegoría sobre la guerra de Argelia, sino su impermeabilidad a las corrientes innovadoras del momento, en un panorama dramático marcado por el teatro del absurdo, la reflexión sobre el lenguaje, el teatro concebido como ceremo- 
nial a la manera de Genet o el influjo poderoso del cine ${ }^{62}$, con un teatro caracterizado mayoritariamente por la ausencia de una verdadera intriga (que será ahora de una banalidad provocadora, o simplemente grotesca, cuando no se trata, simplemente, de la ausencia de cualquier tipo de acción), por unos personajes carentes de la menor profundidad psicológica -lo que los aleja de la categoría de personas y las acerca en su alienación a la condición de cosas-, por la renuncia a la temporalidad de corte clásico o a la necesidad de conferir al drama significación alguna, o por un rechazo radical, en fin, del principio clásico de identificación (del actor con su personaje, y del espectador con la fábula), sustituido, por influjo de Brecht, por el distanciamiento (Brunel 2002, p.193). De hecho, casi todos los dramaturgos que se interesan por la temática de raigambre política se centran, o bien, como ya dijimos, en escenarios alegóricos irreales, o en los temas más actuales o que más preocupan al hombre del momento, pero abordados desde una perspectiva muy diferente a la del teatro tradicional. Michel Vinaver, por ejemplo, el mayor renovador del teatro político de la época, pone en escena la historia tal como la viven los personajes humildes y anónimos: un soldado en la guerra de Corea, en Les Coréens (1956), o unos modestos y atribulados funcionarios de tercer nivel en plena guerra de Argelia (Les Huissiers, 1958), y no los grandes acontecimientos históricos, ni los hechos de los grandes personajes (Brunel 2002, p.195).

Frente a ellos, Geschwin parece un conspicuo representante un tanto trasnochado de todo aquello que el nuevo teatro impulsado por la revolución artística que encabezaron Ionesco, Becket y Adamov vino a dinamitar: la comedia burguesa de diversión, el teatro «literario» y el teatro comprometido; en una palabra, cualquier forma de dramaturgia clásica fundada en la ilusión referencial y en la mímesis (Brunel 2002, p.197). Mientras que los dramaturgos contemporáneos interesados por la historia se ocupan de temas cercanos y candentes ${ }^{63}$, el mundo dramático de Geschwin lo pueblan las revueltas de los proto-franceses contra la dominación romana, la locura de Charles VI (1368-1422), las guerras de religión, los difíciles comienzos del reinado de Louis XIII (1601-1643), el misterioso hombre de la máscara de hierro mantenido implacablemente en prisión durante el reinado de Louis XIV, las guerras napoleónicas o el desdichado Eugenio Bonaparte, epígono insignificante del llamado Segundo Imperio, en ocasiones, además, en dramas escritos, anacrónicamente, en verso. Y, cuando quiere abordar de manera no referencial un problema de la más rabiosa actualidad, como la guerra de Argelia, recurre al empleo alegórico de la mitología clásica, un procedimiento que había resultado impactante un cuarto de siglo antes, con Girau-

\footnotetext{
62 «C’est le cinéma américain qui impose, dans ses œuvres noires ou dans le western lumineux, les décors classiques de la tragédie moderne comme de l'épopée...» (Bancquart- Cahné 1992, p.380).

${ }^{63}$ Es verdad que Arthur Adamov, uno de los renovadores del teatro de los cincuenta, escribió algunos dramas ambientados en periodos históricos no contemporáneos, pero siempre desde una perspectiva revolucionaria que podía fácilmente ponerse en relación con las turbulencias del momento; en Paolo Paoli (1957), por ejemplo, se centra en la violencia de los años que precedieron a la Primera Guerra Mundial, y en Le Printemps 71 (1961), en la experiencia convulsa de la revolución fracasada que supuso la Comuna de París. En La politique des restes (1963), en cambio, se centraría en un tema de rabiosa actualidad como el apartheid.
} 
doux o Sartre ${ }^{64}$, pero que parece difícil no considerar ahora, en los albores de los 60, como francamente démodé. No hay más que comparar la losa de silencio que ha envuelto la tragedia de Geschwin y la tremenda y escandalosa acogida que tuvo Les $\mathrm{Pa}$ ravents de Genet, en que se representan los horrores de una guerra colonial en un país árabe no determinado, colonizado por una potencia europea también sin determinar, pero cuya relación con el conflicto argelino era difícil no percibir. Puesta en escena por primera vez en Berlín en 1961, su estreno en París en abril de 1966 provocó una auténtica conmoción, en la que buena parte de la Francia conservadora que no había digerido aún la derrota en Argelia llevó muy mal las referencias más que evidentes al sangriento conflicto colonial, malestar que se tradujo en manifestaciones violentas de grupos de extrema derecha y excombatientes de las guerras coloniales que Francia había perdido en las últimas décadas, con irrupciones incluso en el propio teatro del Odéon e interpelaciones acaloradas en la Asamblea Nacional, que forzaron a intervenir para aplacar los ánimos al mismo Ministro de Cultura, André Malraux, que se vio obligado a recordar el derecho a la libertad de expresión y creación en defensa de una obra que, en el plano artístico, no era, precisamente, de su agrado (Brunel 2002, pp.214-215).

Sin embargo, consideradas las cosas no desde el punto de vista de la historia de la literatura, con sus modas, sus avances y sus retrocesos, sino desde el quizás menos prestigioso pero no menos relevante de la tradición clásica, resulta conmovedor y gratificante que todavía en la Francia dominada por la sombra de Brecht, de Beckett o de Ionesco, un dramaturgo modesto consternado espiritualmente por el sangriento y fratricida conflicto argelino haya encontrado en la mitología clásica un cauce para expresar de manera artística -y más allá de cualquier moda- su malestar y su oposición radical a la guerra y el belicismo. Si, como quería Gilbert Highet,

La diferencia entre un hombre educado y un hombre sin educación es que el hombre sin educación vive solo para el momento, leyendo su periódico y viendo la última película, mientras que el hombre educado vive en un presente mucho más vasto, en esa eternidad vital en que los Salmos de David, los dramas de Shakespeare, las Epístolas de San Pablo y los diálogos de Platón hablan con el mismo encanto y la misma fuerza que los hicieron inmortales en el instante en que se escribieron (Highet 1949, p.365),

concedamos al menos a Geschwin que, aunque no quiso o no supo sintonizar con las modas de su tiempo, fue capaz, con todo, de instalarse, como tantos otros cultivadores de la tradición clásica, en un presente más vasto que el presente temporal.

\footnotetext{
${ }^{64}$ Es difícil, en efecto, no poner en relación La guerre de Troie n'aura pas lieu (1935) de Giraudoux con una reflexión y un aviso sobre el peligroso camino por el que empezaba a marchar Europa, que llevaría, cuatro años después, a la Segunda Guerra Mundial, o no considerar Les mouches (1943) de Sartre como una alegoría de la resistencia moral ante el horror nazi en la Francia ocupada.
} 


\section{REFERENCIAS BIBLIOGRÁFICAS}

BANCQuART, M.C. - CAhne, P. (1992), Littérature française du XXe siècle, Paris, PUF.

Berrigan, J.R - Tournoy, G. (1980), «Gregorii Corrarii Veneti Tragoedia, cui titulus Progne. A Critical Edition and Translation», Hum.Lov. 29, 13-99.

Bond, F. (2011), «Cantate meco, Progne e Filomena: Riscritture Cinquecentesche di un mito ovidiano», Parole Rubate / Purloined Letters 3.3, 27-62.

Brunel, P. (2002), La littérature française du XXe siècle, Paris, Colin, 2005.

BRENNER, C.D. (1947): A bibliographical list of plays in the French language 1700-1789, Ann Arbor, MI, Edwards Brothers.

CAsarsa, L. (1981), «Gregorio Correr. Progne (a cura di Laura Casarsa)», en Il teatro umanistico veneto. La tragedia, Ravenna, Longo Editore, pp.87-236.

CAstañeda, J.A. (2006), «The Classical Legend of Progne and Filomena in Spanish Golden Age Theater», en Simerka, B. - Williamsen, A.R. (eds.), Critical Reflections. Essays on Golden Age Spanish Literature in Honor of James A. Parr, Lewisburg, Bucknell University Press, pp.102-110.

CAzZANigA, I. (1950-1951), La saga di Itis nella tradizione letteraria e mitografica grecoromana. I: la tradizione letteraria e mitografica greco-romana da Omero a Nonno Panopolitano. II: L'episodio di Procne nel libro sesto delle Metamorfose di Ovidio. Ricerche intorno alla tecnica poetica ovidiana, Varese-Milano, Istituto Editoriale Cisalpino.

Chevalier, J.F. (2010), Trois tragédies latines humanistes, Paris, Les Belles Lettres.

Connon, D. (2007), Identity and Transformation in the Plays of Alexis Piron, Leeds, Leganda.

DeJEan, J.L. (1987), Le théâtre français depuis 1945, Paris, Nathan.

Fialcofschi, R. (2009), «Le "Journal de Paris" et les arts visuels, 1777-1788», Thèse de doctorat de Lettres et Arts, Université Lumière Lyon 2 (theses.univ-lyon2.fr/documents/ getpart.php?id=1294\&action $=p d f)$.

Fortia D’Urban, A. (1817), s.u. «Jean-Baptiste GuYs», en Biographie Universelle Ancienne et Moderne, XIX, Paris, Michaud, p.259.

Gely, V. - Haquette, J.L. - Tomiche, A. (eds.) (2006), Philomèle. Figures du rossignol dans la tradition littéraire et artistique, Clermont-Ferrand, Presses Universitaires Blaise Pascal.

Geschwin, J. (1959), Cléopâtre, tragédie en 4 actes. Charles VI, tragédie en 4 actes. Louis $X V$, tragédie en 5 actes, Montpellier, Imprimerie Causse, Graille \& Castelnau.

Geschwin, J. (1962), Théâtre en prose. Le serment de Procné. Tragédie légendaire en trois actes. La fille de Poltrot. Drame historique en trois actes, Montpellier, Imprimerie de la Charité.

Geschwin, J. (1963), Un duel à Sète, comédie satirique et burlesque en 7 tableaux. L'Homme au masque de fer, énigme historique en 5 tableaux, Montpellier, Imprimerie de la Charité.

Geschwin, J. (1964), Le crime de la rue Barbusse. Comédie dramatique et satirique en dix tableaux, Montpellier, Imprimerie de la Charité.

Geschwin, J. (1966), Saint-Clair 66, poèmes, s. 1. Édition Princeps. imprenta

Geschwin, J. (1968), Saint-Clair 68, poésies nouvelles, Sète, Imprimerie S. Sottano.

Geschwin, J. (1969), Tous les poèmes, Sète. imprenta 
Geschwin, J. (1977), Tragédies. Cléôpatre. Eponine. Charles VI. La fille de Poltrot. Louis XIII. L'homme au masque de fer, Montpellier, Imprimerie de la Charité.

Geschwin, J. (1978), Saint-Clair: anciens et nouveaux poèmes, Montpellier, Imprimerie de la Charité.

Geschwin, J. (1983), Comédies Sétoises. Une femme encombrante. Duel à Sète. Le crime de la rue Barbusse. Le trésor de Rommel. Ali, Baba et les quarante voleurs, Imprimerie de La Charité, Montpellier.

Geschwin, J. (1990), Tragédies nouvelles, Montpellier, Imprimerie de la Charité.

Griffiths, P. (1980), s.u. «Charpentier, Marc-Antoine», en SAdie, S. (ed.), The New Grove Dictionary of Music and Musicians, 4, London, Macmillan (reimpr. 1995), pp.162-176.

Highet, G. (1949), La tradición clásica, II, traducción de A. Alatorre, México, Fondo de Cultura Económica, 1954.

Hunter, M. (1980), s.u. «Lacoste, Louis de», en SADIE, S. (ed.), The New Grove Dictionary of Music and Musicians, 10, London, Macmillan (reimpr. 1995), p.352.

Jouin, H. (1905), Antoine Renou, premier secrétaire de l'Ecole Nationale des Beaux Arts, Vendôme, Imprimé pour l'Auteur par les soins de M. Vilette.

Marcello, E. (2008), «Reescrituras teatrales del mito de Progne y Filomena. G. Correr, L. Domenichi y G. Parabosco», en Herrero Cecilia, J. - Morales Peco, M. (eds.), Reescrituras de los mitos en la literatura. Estudios de mitocrítica y de literatura comparada, Cuenca, Universidad de Castilla-La Mancha, pp.151-166.

Marchal-Ninosque, F. (2003), «Le théâtre d'Antoine-Marin Lemierre, une école des citoyens», Revue d'Histoire Littéraire de la France 103.1, 49-62.

Martín Rodríguez, A.M (2002), De Aedón a Filomela. Génesis, sentido y comentario de la versión ovidiana del mito, Las Palmas de Gran Canaria, ULPGC.

MARTín RodríGuez, A.Mª (2008a), «Imágenes de la mujer transgresora en los Siglos de Oro. Algunas versiones dramáticas del mito de Filomela», en NIETO IBÁÑEZ, J.Ma . - MANCHÓN López, R. (coord.), El humanismo español entre el Viejo Mundo y el Nuevo, León, Universidad de Jaén - Universidad de León, pp.263-286.

Martín Rodríguez, A.Ma (2008b), El mito de Filomela en la literatura española. León, Universidad de León.

MARTín RodríGueZ, A.Ma (2008c), «La figura de Tereo en el teatro francés del siglo XVIII: el Terée de Antoine-Marin Lemierre», Fortunatae 19, pp.41-61.

Martín Rodríguez, A.Ma (2009), «La Philomèle de Pierre-Charles Roy y Louis de Lacoste (1705): una influyente versión francesa del mito de Progne y Filomela», Annals of the University of Bucharest. Foreign Languages and Literatures. Part I 58, 3-16.

Martín Rodríguez, A.M ${ }^{a}$ (2010), «El teatro humanístico latino en la Inglaterra jacobea: el drama Philomela (1607)», en Viforcos Marinas, Mª I. - CAMpos SÁnchez-Bordona, $\mathrm{M}^{\mathrm{a}}$ D. (coord.), Otras épocas, otros mundos, un continuum, Madrid, Tecnos, pp.194-213.

MARTín Rodríguez, A.M (2011), «Una versión paródica del mito de Filomela: la Philomèle de Alexis Piron (1723)», en Hernández GonzÁlez, F. - Martínez Hernández, M. Pino Campos, L.M. (eds.), Sodalium Munera. Homenaje a Francisco González Luis, Madrid, Ediciones Clásicas, pp.327-336.

Martín Rodríguez, A.M (2013), «Una tragedia por desafío: Térée et Philomele (1773) de Antoine Renou», Fortunatae 24, 61-82. 
MCVAY Jr., T.E. (1994): «Sebastián y Latre’s refundición of Rojas Zorrilla’s Progne y Filomena as a reflection of social change», en RicAPITO, J.V. et al. (eds.), Selected Proceedings. Louisiana Conference on Hispanic Languages and Literatures, Baton Rouge, Louisiana State University, pp.161-168.

Mihailov, G. (1955), «La légende de Térée», Annuaire de l’Université de Sofia 50, 77-208. Monella, P. (2005) Procne e Filomela: dal mito al simbolo letterario, Bolonia, Pàtron Editore.

Ojeda Calvo, M ${ }^{\mathrm{a}}$ V. (2006), «Progne y Filomena: una tragedia recuperada de la colección Gondomar», en Gorsse, O. - Serralta, F. (coord.), El Siglo de Oro en escena: Homenaje a Marc Vitse, Toulouse, Presses Universitaires du Mirail, pp.661-680.

Polinger, E.H. (1930), Pierre Charles Roy: Playwright and Satirist (1683-1764), New York, Publications of the French Studies.

Ponce, N. (1824), s. u. «RENOU (ANTOINE)», en Biographie Universelle Ancienne et Moderne, $X X X V$, Paris, Michaud, pp.436-437.

REID, J.D. (1993), The Oxford Guide to Classical Mythology in the Arts, 1300-1990s, New York, Oxford University Press.

Richards, E.J. (1982), The Christmas Prince (acted 1607/8), prepared with an Introduction by Earl Jeffrey Richards, Hildesheim, George Olms.

Rovani, G. (1856), Storia delle Lettere et delle Arti in Italia giusta le reciproche loro rispondenze, ordinata nelle vite e nei ritrati degli uomini illustri dal secolo XIII fino ai nostri giorni, per cura di Giuseppe Rovani, II, Milano, per Borroni e Scotti, pp.445-447. (http://books.google.es/books?id=15BAAQAAIAAJ\&pg=PA455\&lpg=PA455\&dq=cant elli+tagliazucchi\&source $=$ bl\&ots $=A X w C G 3 B J C U \&$ sig $=$ jvr-DmWx_bQ4aIWsRKae4E 7CAyo\&hl=es\&sa $=$ X\&ei $=$ AgZdVMakNfiTsQSfo4LACA\&ved $=0$ CFUQ6AEwDA\#v $=0$ nepage \&q=cantelli\%20tagliazucchi $\& \mathrm{f}=$ false)

Smits-VeldT, M.B. (1986), Samuel Coster, ethicus-didacticus: een onderzoek naar dramatische opzet en morele instructie van Ithys, Polyxena en Iphigenia, Groningen, Wolters-Noordhoff/ Forsten.

Sutton, D. (2006), The Anonymous Tragedy Philomela (1607). A Play from the Christmas Prince cy〈c〉le. A hypertext critical edition by Dana F. Sutton, The University of California, Irvine. Posted September 23, 2006. Revised October 3, 2006: http://www.philological. bham.ac.uk/philomel/.

Vellón Lahoz, J. (1994): «El Ensayo sobre el teatro español de Sebastián y Latre: la refundición del teatro barroco como instrumento ideológico», Dieciocho 17.2, 165-176.

Vereb, P. (1997), Alexis Piron, poète (1689-1773) ou la difficile condition d'auteur sous Louis $X V$, Oxford, Voltaire Foundation. 